\title{
Reduction of Heat Emission to Surroundings from Improved Wood Burning Stove
}

\author{
ZAKARIYA KANEESAMKANDI \\ Mechanical Engineering Department, College of Engineering, \\ King Saud University, Riyadh - 11421Saudi Arabia. \\ http://dx.doi.org/10.12944/CWE.9.3.04
}

(Received: October 05, 2014; Accepted: October 24, 2014)

\begin{abstract}
Apart from emissions and inefficiency, heat generation from wood stoves to the surroundings is another undesirable effect causing health repercussions especially in the small dwellings of tropical regions. The present research addresses this problem. Steady state temperature measurements on the surface of the improved wood burning stove is used to determine this loss in which chimney draft control plays an important role. Experimental results were in good agreement with that of the model simulated using the commercial computational fluid dynamics code. A modified model in which changes were introduced to reduce the radiation and convection losses from the stove to the surrounding regions was simulated. Firstly, the radiation losses from the fire was reduced by reducing the size of fuel supply port. Secondly, a waste heat recovery system was introduced which resulted in lower stove body temperature. This was done by optimizing the use of the draft produced by the chimney. Results of the modified model of the stove showed a reduction of this loss by $12.08 \%$. Stoves currently used under the national project for rural energy development was used for this purpose. Apart from improving the stove efficiency, this development will have a positive impact on the acceptability of the improved wood stove in rural households and also help to further reduce fuel consumption.
\end{abstract}

Key words: Heat emission, Chimney optimization, Wood burning stove, Efficiency enhancement and Waste heat recovery.

\section{INTRODUCTION}

Improved wood stoves have the potential to produce a significant impact on the rural economy, quality of life, indoor air quality, afforestation and global warming since more than half of the global human population depends on firewood for their cooking energy needs. These stoves were introduced in many developing countries with more stress on rural households and rural based commercial applications. Michael Johnson et al. ${ }^{1}$ gave a complete picture of the biomass stove programs in India, Nepal and Peru. Efficiency improvement in the improved stoves and environmental advantages are brought forth. Both natural draft stoves that use a chimney for regulating the air flow and forced draft stoves which use a fan for this purpose were developed. While the former was mostly used in households, the latter was used for large scale cooking and other industrial applications. Improvement in efficiency in a chimney stove was done by using insulation with charred rice husk around the stove and efficiency improvement from 9.6 percent to 10.11 percent was reported by Yutana Sriudom ${ }^{2}$. Elaborate description of wood burning stoves and their performance comparison has been provided by Raman et al. ${ }^{3}$.

Escalation in the cost of fuel wood has created a severe impact on the acceptability of improved wood stoves as a viable option to overcome the escalating cost of electricity and liquefied petroleum gas for cooking applications in rural households in India. Reducing the fuel consumption by introducing energy efficiency options will help to 
increase the acceptability of the improved firewood stoves. A study was conducted by Kishore and Ramana ${ }^{4}$ on the status of the National Program on improved cook stoves and it was concluded that user acceptance is one of the factors which reduced project progress.

Several angles of approach have been adopted by researchers to increase the efficiency and reduce the fuel consumption and emissions from the improved stoves. These include modifications in the combustion chamber, reduction of convection and radiation losses or improving fuel quality. Efficiency enhancement by modifying the combustion chamber by using baffles were tested and reported to give $12 \%$ improvement in the overall efficiency with other benefits of low emissions and longer operating life $\left(\right.$ Erick Boy et $\left.{ }^{5}\right)$. Experimental studies on the effect of different operating conditions on the overall efficiency of wood burning stoves was done and it was concluded that up to $12 \%$ increase in the efficiency is possible (Juan and Rodrigo ${ }^{6}$ ).

Air flow rate in natural draft stoves which is produced by the chimney effect plays an important role in controlling the efficiency, emissions and heat losses. Mathematical models were developed to study the effect of chimney height and diameter on the temperature profile for wood stoves and results were compared with that of true values and similarity was reported by Joshua et al. ${ }^{7}$. Thermal efficiency enhancement of $15 \%$ was reported by providing extra air supply during the combustion process (Ravindra Mohan and Shankar Kumar ${ }^{8}$ ). Effect of waste heat recovery on different types of biomass stoves were discussed and its impact on efficiency enhancement was given by Lokras ${ }^{9}$. This paper aims at determining the actual effect reducing heat losses in a wood burning stove.

The objectives of the present study are as follows:

- To measure the performance parameters and to determine the efficiency of the conventional improved wood burning stove

- $\quad$ To make a two dimensional model of the air flow system in the conventional improved wood burning stove and to simulate its performance using commercial computational fluid dynamics (CFD) code followed by a comparison of the model with the experimental results.

- To numerically estimate the performance of the stove after introducing the waste heat recovery mechanism.

\section{MATERIAL AND METHODS}

\section{Stove construction and operation}

The double pot cook stoves ${ }^{1}$ developed and implemented in the rural and tribal areas is used for the present study. Most of the improved cook stoves used around the world operate on similar principles and the improvements proposed in this study are applicable for all these stoves. They are mostly built of clay because of local availability and low cost. Sometimes they are made of heat resistant refractory cement but at higher cost. Fig. 1 (a) gives the general arrangement of the stove and the detailed sectional view along with the major dimensions are given in Fig.1 (b).

The fuel supply port also acts as the air supply port and the draft produced by the chimney produces the movement of air all the way to the chimney exhaust. The high temperature gaseous products of combustion provide the energy for cooking at the primary and secondary levels at heights of $21 \mathrm{~cm}$ and $27 \mathrm{~cm}$ respectively. Eq. 1 gives the relation between the height $(\mathrm{H}$, meters) of the chimney, the density of the gas $\left(\tilde{\mathrm{n}}, \mathrm{kg} / \mathrm{m}^{3}\right)$ and the suction pressure ( $\mathrm{A} \mathrm{P}, \mathrm{Pa}$ ) produced by the chimney. Under ideal conditions, this pressure drop is usually greater than or equal to the pressure drop due to air flow through the stove ().

$$
\Delta P=g H\left(\rho_{5}-\rho_{\mathrm{I}}\right)=\Delta P_{\hat{H}}
$$

In the above equation, subscript ' $b$ ' and ' $t$ ' indicate the chimney bottom and top. The term ' $g$ ' represents the gravitational constant, $9.81 \mathrm{~m} /$ $\mathrm{s}^{2}$. As the temperature of the gas at the bottom of the chimney increases, the density decreases and this results in a higher suction pressure and therefore more air flow which produced higher losses. Reduced suction pressure is also undesirable because this will cause reduced air flow and poor combustion efficiency. 
In this research, the radiation and convection losses from the stove are minimized by making the following two modifications in the stove design. These are:

- Reducing the size of the fuel supply port from the present level of $17 \mathrm{~cm} \times 15 \mathrm{~cm}$ to $10 \mathrm{~cm}$ $x 15 \mathrm{~cm}$

- $\quad$ Provision of an air supply port which recovers part of the heat produced and stored in the body of the stove. The hot air is delivered at the bottom of the fuel firing zone.

Optimum size of the heat recovery port and fuel port were determined by equating the pressure drop produced by the chimney and total pressure

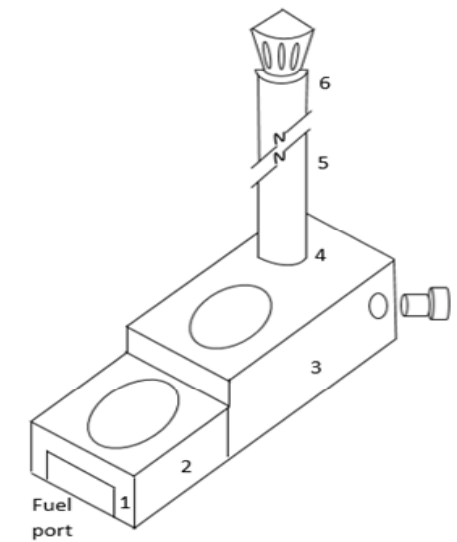

dropat the fuel port ()andthe heat recovery port () as given in Eq.2 and using standard equations for pressure drop calculations.

$$
\Delta P_{C}=\Delta P_{t}+\Delta P_{b}
$$

The sectional elevation of the modified arrangement is shown in Fig.2. In this arrangement, the fuel inlet port is reduced in dimension and air supply port has been introduced below the firing zone. Since the thermal conductivity of the clay out of which the stove is made is poor and because of heat storage, there will be a considerable time gap for reaching steady state.

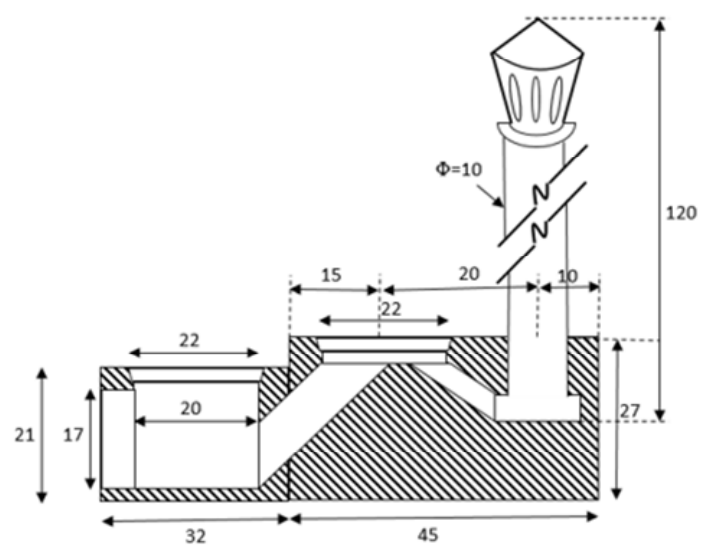

Fig.1: (a) General arrangement of improved wood burning stove with temperature measurement points (b) Cross sectional view with dimensions

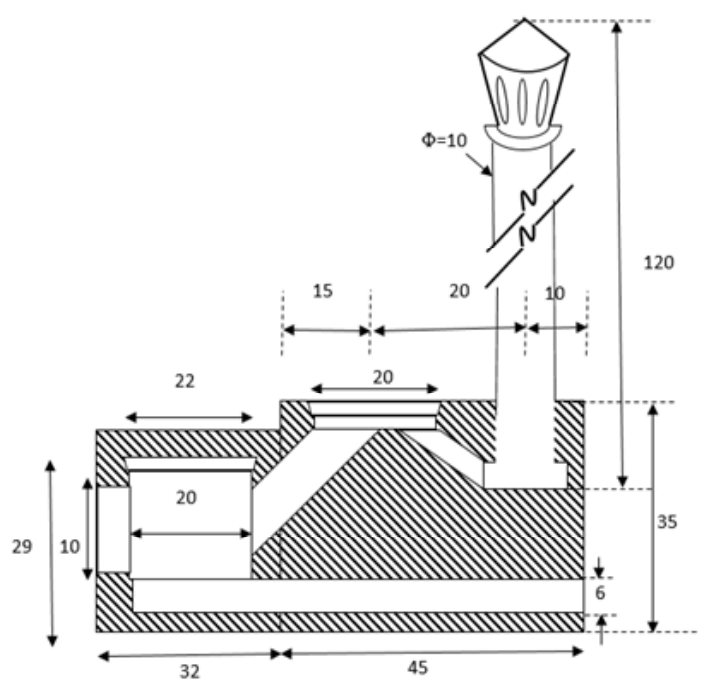

Fig. 2: Sectional elevation of the modified wood burning stove
Efficiency of the wood burning stove depends on the magnitude of the following heat values which again depends on the stove design and performance.

1. Heat supplied by the fuel burnt, $\mathrm{H}_{f}, \mathrm{~kJ}$

2. Useful heat supplied to the vessels, $\mathrm{H}_{\mathrm{u}}$, kJ

3. Flue gas loss through the chimney, $\mathrm{H}_{\mathrm{g}}, \mathrm{kJ}$

4. Unburnt carbon loss, $\mathrm{H}_{\mathrm{C}}, \mathrm{kJ}$

5. Ash sensible heat loss, $\mathrm{H}_{\mathrm{a}}$, $\mathrm{kJ}$

6. Radiation and convection losses from surface of the stove, $\mathrm{H}_{\mathrm{s}}$, $\mathrm{kJ}$

Efficiency of the stove is given by the following relation:

$$
\mathrm{h}=\frac{H_{u}}{H_{J}}=\frac{\left\lfloor H_{J}-H_{u}-H_{\mathrm{g}}-H_{c}-H_{\mathrm{a}}-H_{s}\right\rfloor}{H_{J}}
$$




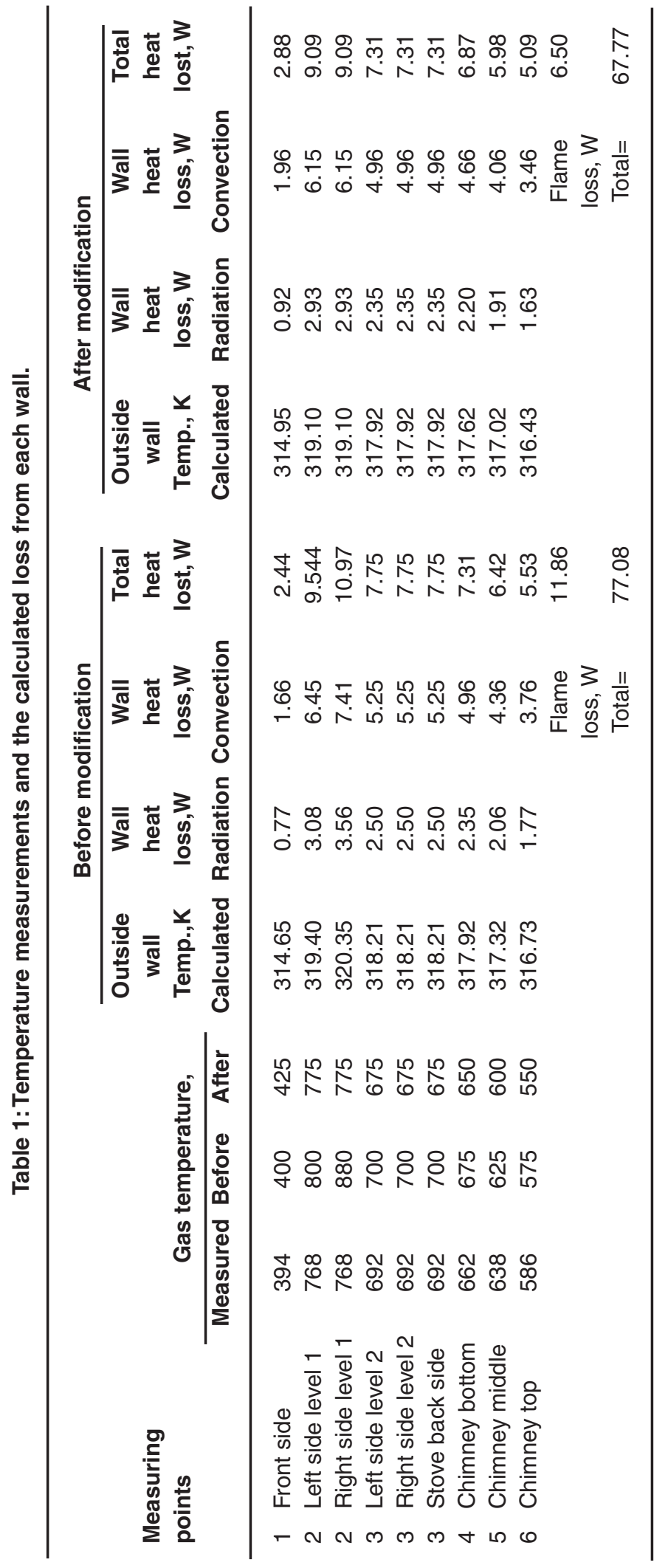


Radiation and convection losses from the surface of the stove () and from the flames through the fuel port are the main sources of heat loss from the stove and which produce considerable loss in stove efficiency. The aim of this study is to reduce these losses.

\section{Measurements and calculation}

In order to determine the total heat loss from the surface of the stove and from the flames to the atmosphere, the following relation is used:

$$
H_{1}=\sum\left[A_{s} \times\left(T_{1}^{4}-T_{0}^{4}\right)\right]+\sum\left[A_{s} \times h_{\mathrm{r}} \times\left(T_{1}-T_{0}\right)\right]+\left[F_{\beta \pi} \times A_{60} \times 5 \times\left(T_{i T T}^{4}-T_{0}^{4}\right)\right.
$$

$A_{S}$ is the outside surface area, $\mathrm{m}^{2}$

$T_{S}$ is the surface temperature of the stove, $\mathrm{K}$

$A_{f p}$ is the area of the fuel port opening, $\mathrm{m}^{2}$

$T_{A F T}$ is the adiabatic flame temperature, $\mathrm{K}$

$\sigma$ is the Stefan-Boltzmann constant for radiation heat transfer, $\mathrm{W} / \mathrm{m}^{2} . \mathrm{K}^{4}$

$P_{f W}$ is the radiation shape factor from the flame to the facing wall surface

Temperature measurements were done inside the stove and chimney at six locations as illustrated in Fig.1a above indicated by numerals 1 to 6. The external wall temperature was then measured using the Fourier law of heat conduction. Eq.4 was used for calculating the total loss from all the walls by adding up the convection losses and radiation losses from each side of the stove. The temperature measured at point 3 was used to find the losses from the back side of the stove.Adiabatic flame temperature $\left(\mathrm{T}_{\mathrm{AFT}}\right)$ and fuel calorific value are obtained using the standard procedure (Bhat and Vora ${ }^{10}$ ) for the chemical composition of the locally available

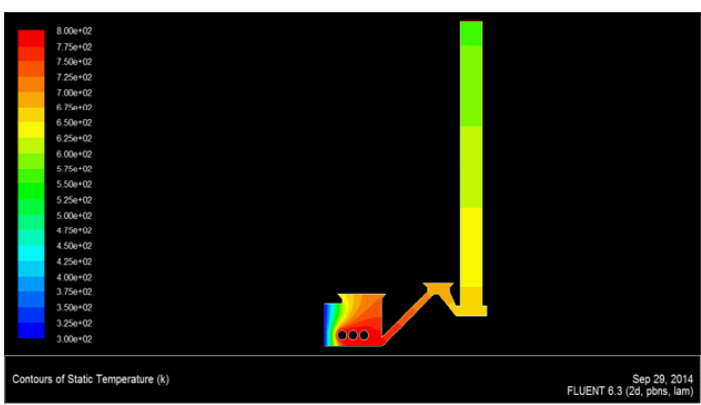

Fig. 3: Contours of static temperature inside the gas flow passage before modification firewood Prosopis Juliflora ${ }^{11}$ which was used during the experiment. $\mathrm{K}$ type thermocouples were used and data acquisition system was used to record the temperatures. The temperature measurements were taken after the stove reached steady state conditions. Outside wall temperature was calculated using Eq.5. It was assumed that inside wall temperature is equal to the gas temperature inside the stove. Heat transfer coefficient on the outer walls, ${ }^{{ }_{C}}$ was calculated using the Jurges equation ${ }^{12}$ for a wind flow of $1 \mathrm{~m} / \mathrm{s}$. Thermal conductivity value for clay (stove material) was taken from available data ${ }^{13}$.

$$
T_{F}=\frac{\left(h_{c} \times T_{A}\right)+\left(k_{c} \times T_{B}\right)}{\left(h_{c}+k_{c}\right)}
$$

\section{Model analysis}

A two dimensional model of the gas flow passage of the wood burning stove was constructed using a commercial modelling tool. The number of triangular cells used was 1914. The gas flow passage consisted of the fuel and air inlet port and the flue gas outlet port from the chimney top. The fuel burning zone (grate) was maintained at the adiabatic flame temperature condition. The inlet temperature of the air for combustion is at $300 \mathrm{~K}$. The inlet and outlet were considered as inlet and outlet vents. Natural convection operating conditions were activated with the Boussinesqapproximation for buoyancy flow. The solution converged after 810 iterations.

\section{RESULTS AND DISCUSSION}

Fig. 3 gives the contours of static temperature inside the gas flow passage of the wood stove before the modifications were made. The temperature contours indicate an average temperature of $700 \mathrm{~K}$

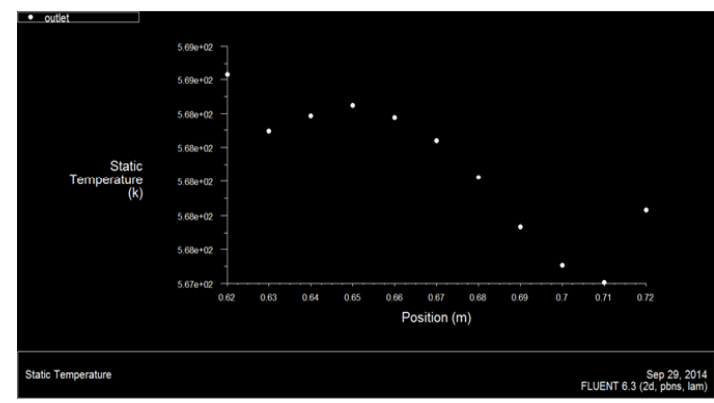

Fig. 4: Static temperature plot of gas at the outlet of the chimney 
and $675 \mathrm{~K}$ at the primary and secondary cooking levels. The temperature of the gases at the chimney range from a lower level of $575 \mathrm{Kat}$ the tip and $675 \mathrm{~K}$ at the base.

Fig. 4 gives the static temperature plot at the outlet of the chimney. The average temperature is $568 \mathrm{~K}$ at the chimney outlet. Fig. 5 gives the temperature contours for the case of the modified stove. Reduction in the size of the fuel port has significant impact on the gas temperature within the stove. Also the heat recovery process helps to increase useful heat. This is evident from the gas temperatures at the primary and secondary levels which are $750 \mathrm{~K}$ and $700 \mathrm{~K}$ respectively. This is $7.14 \%$ and $3.7 \%$ higher than the previous case.

Fig.6 gives the plot of the temperature of the gas at the outlet of the chimney for the case of the modified stove. The average temperature is reduced to $496 \mathrm{~K}$ compared to $568 \mathrm{~K}$ for the earlier case. Table 1 gives the results of the experiment as well as the simulation for the two cases, namely,

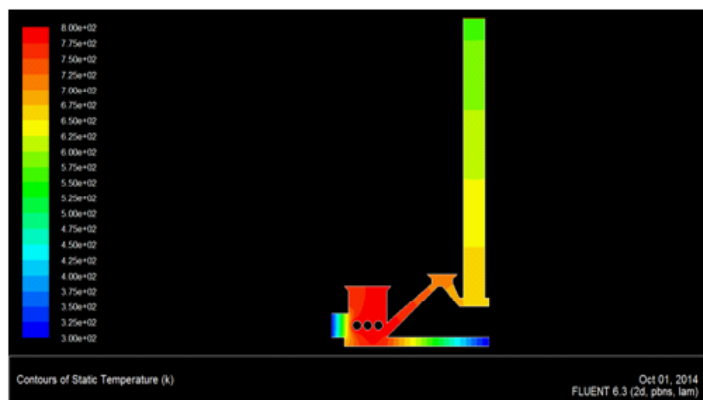

Fig. 5: Contours of static temperature of the hot gas for the modified stove before and after the modification. The heat lost by radiation and convection is reduced by $12.08 \%$ after the modifications are made.

Fig. 7 gives the comparison of the temperature profile for gas inside the chimny at the three points for the three cases, namely, experimental case before modification, the simulation result before modification and the simulation result after modification.Experimental measurement of gas temperatures at the different points are in agreement with that of the model.

\section{CONCLUSION}

An experimental study of the heat loss from the surface of improved wood burning stove was conducted. Internal gas temperature measurements were made from which external surface temperatures were calculated. Internal gas temperatures were compared with the results of the model and were found to be in agreement. Heat loss from the surface of the stove and chimney were calculated and the

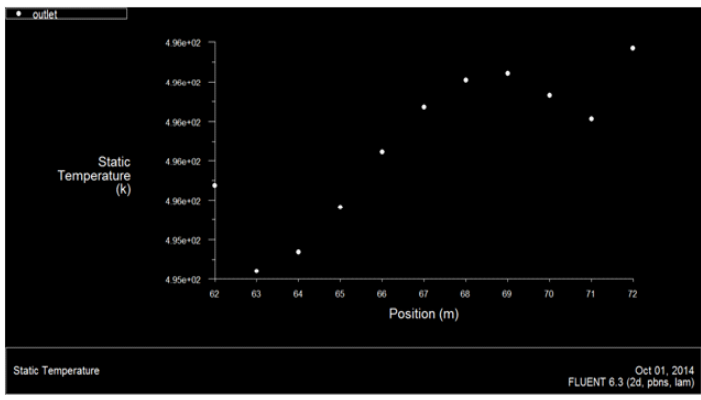

Fig. 6: Temperature plot for gas at chimney outlet for the modified stove

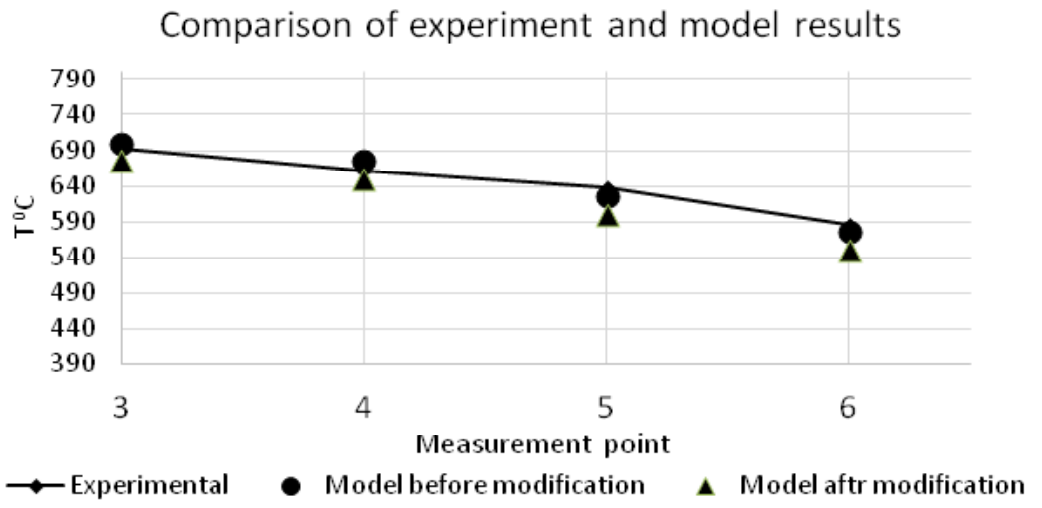

Fig. 7: Comparison of experiment and model results of temperature 
effect of the modifications on the stove performance and heat loss was calculated. Stove temperatures at the primary and secondary level increased by $7.14 \%$ and $3.7 \%$ respectively. It was found that heat loss was reduced by $12.08 \%$ by the modification. Further experimental investigation on the improved stove is necessary.

\section{ACKNOWLEDGEMENT}

The author hereby acknowledges the support from the Deanship of Research, College of Engineering, King Saud University for successful completion of this study.

\section{REFERENCES}

1. Michael A. Johnson, VerónicaPilco, Rafael Torres, Sandeep Joshi, Rajeev M. Shrestha ${ }^{e}$, MaheshYagnaraman, Nicholas L. Lam, Brenda Doroski, John Mitchell, Eduardo Canuz, David Pennise. Impacts on household fuel consumption from biomass stove programs in India, Nepal, and Peru. Energy for Sustainable Development. 17(5), 403411(2013).

2. YutanaSriudom, Thermal efficiency improvement and technology transfer of chimney stove for producing stove; Amphoe Bo Kluea, Nan Province. Energy Procedia. 9: 238-244 (2011).

3. P. Raman , J. Murali, D. Sakthivadivel, V.S. Vigneswaran Performance evaluation of three types of forced draft cook stoves using fuel wood and coconut shell. Biomass and Bioenergy. 49,: 333-340.

4. V.V.N. Kishore and P.V. Ramana. Improved cookstoves in rural India: how improved are they? A critique of the perceived benefits from the National Programme on Improved Chulhas (NPIC) Energy 27; 47-63 (2002).

5. Erick Boy, Nigel Bruce, Kirk R. Smith, Ruben Hernandez. Fuel efficiency of an improved wood-burning stove in rural Guatemala: implications for health, environment and development. Energy for Sustainable Development. 4(2); 23-31 (2000).

6. Juan A. Guzman, Rodrigo Jordan. Evaluation of possible energy savings through energy efficiency increase in domestic wood stoves. Resources and Conservation. 151(2); 113124 ((1987)).

7. Joshua Agenbroad, Morgan DeFoort, Allan Kirkpatrick, Cory Kreutzer (2011) A simplified model for understanding natural convection driven biomass cooking stoves-Part 1: Setup and baseline validation. Energy for Sustainable Development, (15)2; 160-168 (2011).

8. Mohan R, Kumar S. Enhancement of Thermal Efficiency of Traditional Indian Cooking Furnace (Chulha). Current World Environment, 6(1); 61-66 (2011). Available from: http://www.cwejournal.org/?p=1274

9. Lokras, S.S., Development and Dissemination of Fuel-Efficient Biomass Burning Devices, Journal of the Indian Institute of Science; 92(1); 99-110 (2012).

10. Bhat, V.I. and Vora, S.M. Stochiaometry. Tata McGrawHill Publishing Company Ltd., New Delhi (2004).

11. Nellie M. Oduor ${ }^{\star}$ and Joseph K. Githiomi. Fuelwood energy properties of Prosopisjuliflora and Prosopispallida grown in Baringo District, Kenya. 8(21); 2476-2481 (2013).

12. Jurges, I.W. Der Warmeubergang an einerebenen wand, BiehefteZumGesundheitsIngenieur, Rehihe-1, Beihefte (1924).

13. http://www.engineeringtoolbox.com/thermalconductivity-d_429.html 